\title{
The Analysis on English Translation of Food Culture in Huimin Street, Xi'an and its Significance on Teaching
}

\author{
Song Yuanyuan \\ Xi'an University, School of Foreign Studies, Shaanxi, China, 710065
}

Keywords: Xi'an; Huimin Street; Food Culture; English Translation

Abstract: Food is a name-card. All countries have their long and splendid food culture. As an ancient capital with profound cultural heritage, $\mathrm{Xi}$ 'an has a wide variety of food, which makes visitors come here and unforgettable. Huimin Street is the main collective place for Xi'an food culture. This paper illustrates the relationship between food and culture, culture and translation, also analyzes briefly the English translation of food culture in Huimin Street, Xi'an and point out its teaching meaning.

Xi'an was named by Chang'an during the prosperous time of the Tang Dynasty. It's located in the middle of the Guanzhong Plain, south of the Qinling Mountains, and north of Lishui, with a very superior geographical advantage. Over the long history with more than a thousand years, Xi'an has always been the political, economic and cultural center of overall China or the Western region. Among the seven ancient capitals of China, Xi'an is the most ancient capital with the longest history and the largest scale.

Xi'an owns the prosperous and profound cultural heritage, attracting a large number of tourists from all over the world every year. Tourism has become one of the most important support $\mathrm{s}$ in Xi'an's economic development. Of many cultural cards in Xi'an, the food culture is an important part of Xi'an culture. People who have been to Xi'an have highly praised Xi'an snacks. As one of the representative places of Xi'an style, Huimin Street in Xi'an is composed of several streets including Beiguangji Street, Beiyuanmen, Xiyang City, Dapiyuan, Huajue Lane and Sajin Bridge. Huimin Street in Xi'an has a profound cultural heritage, and a large number of food shops are building on both sides of Huimin Street. There are nearly three hundred kinds of various foods in Huimin Street. For example, the well-known beef and mutton foam is a rare tonic, which is strongly tasted and delicious.

In recent years, as the number of tourists rapidly increase, many scholars have begun to undertake English translation of Xi'an food culture. As far as the author is concerned, it's a very systematic project to do a good job in the English translation of the food culture. In order to do this work, it requires not only the solid foundation of English, but also a deeper understanding of the relationship between culture and food, culture and translation.

\section{Food and Culture}

The relation between food and culture is close. Different cultures play a profound influence on the food. From some perspective, food itself is a cultural symbol. The Chinese-Western cultures 
have the huge difference. Therefore, the Chinese-Western has different understandings and connotations about food culture. Chinese people have been paying much attention on the food. There is a saying among the folks that the people regard food as their sky and the food with taste placing the first. While pursuing for delicious taste in the Chinese food culture, Chinese people also pay special attention to health by means of dietary food. The Western cooking mainly focuses on nutrition, while often ignores the taste of food. With much attention to nutritional value, Western people prefer to raw fruits and vegetables. They not only have tomatoes, yellow flowers, etc., but also even onions, cabbage and broccoli, etc., which we think hard to swallow, are just a simple dish on the table. Truly, we also know that vegetables and other vegetables will inevitably lose some nutrients after cooking and processing. However, due to the influence of long-term food culture, between both, the Chinese have been weighing and prefer the taste of food to its nutrition. On this basis, we strive to achieve a balance between nutrition and taste, which somewhat reflects the doctrine of the mean in Chinese traditional culture.

The pursuit of food culture for Chinese also embodies the word beauty. This beauty embodies not only in cooking process, but also in the final dishes and even the name. For example, Chinese food often has poetic and artistic names, such as Peacock Greeting Dish, Half of Moon Falls River Dish, and Peach Garden Oath Dish, etc., which are too numerous to list. Good names often make people drool. The color and flavor is the simplest requirement for the Chinese food, and also the essence of Chinese food culture. If the color and flavor is only popular in the form and can only be the food package, then the taste is the content and essence of the Chinese food. The unique charm of Chinese food culture fully embodies the unification thought of Chinese traditional culture that the world is a family, and all begin from the overall situation.

The Western food culture is duller, regardless of the selection of ingredients or the cooking process. Though the Western food has matching combination, this combination is just a simple patchwork. For example, we often see that the French mutton chops are to place lamb chops on one side, also additional green beans and a few tomatoes. This collocation is obviously larger than the form, in which the basic elements are independent with each other and irrelevant. There is no reconciliation in the Chinese food culture, which cannot be called art. Western food culture overall emphasizes that they are more scientific, rational and nutritious. This concept is somewhat mechanical in the eyes of the Chinese. As for the name of the dish, Westerners are generally pay little attention to it, as long as they can basically describe the basic feature of the food. Therefore, many foreigners is stunned hearing the name of a Chinese food, they really do not know how the name is related to the specific dishes. For this, many foreigners who first arrived in China made a lot of jokes. I once heard a friend mention and he invited a few foreign friends to have dinner, ordering a dish that is called the Ants Climbing on Trees. This dish is not strange to most Chinese people. When foreign friends heard the name, they couldn't help but face each other, and expressed embarrassment. They intuitively thought that this dish had an inevitable connection with the ants. After Chinese friends explained in detail, foreign friends felt relieved, and the hanging heart got calm. Later on, these foreign friends praised the taste of the dish, but the name was still a bit unrecognizable.

\section{Culture and Translation}

What is translation? From some perspective, translation is a conversion of culture. Culture is the general term for material wealth and spiritual wealth created by human beings in the process of social development. The culture generally means the synthesis of material culture, mental culture, and institutional culture. From the appearance, translation seemingly is only a matter of language. Actually, the process of translation is that of cultural re-processing, that of cultural information 
transmission, and that of language transmission. As a person for translation, if you stay away from the culture to do translation work, you can't translate the more concealed cultural factors in the translated content, or the translating results are far from the original meaning. As a translator, while properly understanding the facial meaning of a language, more attention should be paid to how to process and synthesize the cultural information in the language, and finally express it in the form of art. The famous anthropologist Yag once put that when people learn a new language, some things are easy to understand, to learn, and can be mastered by increasing vocabulary and mastering some grammar rules. There some things more difficult to learn, such as the difference among the languages, which is very complicated and much different from the view that we usually treat the world. The huge differences between different cultures have brought enormous challenges to translation.

\section{English Translation of Food Culture in Huimin Street, Xi'an}

Huimin Street is a window of Xi'an. The ethnic food culture is an important part of Chinese and foreign cultural exchanges. Undoubtedly, Huimin Street is the frontier of this exchange which is an important link to promote the specialties of Xi'an Huimin to the world, promote the exchange and prosperity of the local culture in Xi'an and world's food culture. In this context, the research of the food names in Huimin Street has a realistic and profound significance.

The translation of Chinese dish names can be traced back to the Qing Dynasty. At that time, many Chinese people set Chinese restaurants in the British territory to make a living. From then on, the English translation of Chinese dishes originated. Since the reform and opening up, if the translation of Chinese dish names is not only as simple as the name of the dish, which can be used as a exchange tool at the state banquet. At present, English translation for Chinese dish names is generally divided into the literal translation, liberal translation, and transliteration. The literal translation feature allows customers to intuitively know the ingredients, tastes and cooking methods of the dishes. For those dishes of simple processing of raw materials, the ordinary production process, names of the dishes without containing cultural connotation, will use literal translation more popularly. The names of the dish thus translated are simple and succinct, which can achieve the smooth and natural feature of the interpretation standard.

Liberal translation allows foreign customers to fully understand the Chinese cultural connotations represented by the dish name. Because the linguistic features of the rich food culture contained in the dish name often cannot find equivalent language vocabulary expression in English culture, the liberal translation is often used. In order to stimulate the appetite of customers, often the dishes a meaningful name is given in Chinese food culture, sometimes such words as auspicious, festive, good luck are applied to the dish name. For example, the chicken is said to be a phoenix, and the snake is to be a dragon. Meanwhile, in the translation of the dish name, we should take the ingredients and cooking methods of the dishes as the core of translation, and express them by means of liberal translation, such as the multi-layer steamed bread and the Guokwei (Dried bun).

The translation of the dish name starting with a person's name or place name is often processed by transliteration. It is also common for Chinese dishes to be transliterated. Some Chinese dishes have a distinct ethnic culture, and it is difficult to find an equivalent word when translating. At this time, it is often appropriate to adopt transliteration. The appropriate use of transliteration can not only avoid misunderstanding and un-legibility caused by literal translation and liberal translation, but also make Chinese food culture spread with its original mean.

Certainly, the literal translation, liberal translation, and transliteration are not mutually contradictory. We often combine the three in the translation process. For example, as Lantian 'belt' noodles, Xinjiang noodles and so on. There are also many translations of dish names in Huimin 
Street, which are also the result of the combining use of the above three translation method, such as the well-known Chinese and foreign, with English translation of the crude pancake in mutton soup, cold rice noodles, Chinese hamburger, Clay oven rolls, Steamed buns, Salted duck egg, Jello Stew with Rice Noodles, Vegetable Stew Lamb Ball, Algae Dumpling, honey glutinous Rice, Qishan Noodles with Ground Pork, Stir-fried starch Rice Tofu, Vegetable Tofu Deluxe, Crispy Fried Noodles, western Style picklcd vegetakli Noodles, Pork Pot Sticker, Rinse tripe and so on.

Nowadays, as Xi'an tourism continuously increases, more and more scholars are paying attention to the cultural transliteration research of Huimin Street snacks. They try to translate the English names of many traditional snacks more scientifically and aptly through their own efforts, which enables the tourists can better understand the cultural heritage of Xi'an over the millennium through the names of these snacks, appreciate the food culture of Xi'an, and understand the poetic conception of Chinese language.

In view of the author's observation, there are still some irregularities in the English translation of some advertisement signs in Huimin Street. Some are irregularities in grammar, some are semantically ambiguous, and some are short of cultural connotations.

\section{The Teaching Guiding Significance of the English Translation Research of Food Culture}

The research of transliteration of food culture has important guiding significance in educational teaching. Firstly, it should be put that transliteration of food culture is a difficult field of translation. Our application in this field can be applied to the practice of educational teaching which enables students to fully understand the close relationship between culture and translation. So students can fully understand the important role of the food culture in translation. Secondly, the English translation of food culture generally requires the combined use of literal translation, liberal translation, and transliteration methods. In the process of educational teaching, we can take some dish as an example to illustrate the comprehensive application of translation methods to students. This teaching method can deepen students' mastery of translation application. Finally, the transliteration research of the local food culture allows students to focus on the research of local culture and further close the relationship between education and practice.

\section{References}

[1] Feng Qinghua. The Practical Translation Course [M]. Shanghai: Shanghai Foreign Language Education Press, 2008: 3.

[2] Wang Enke, Li Xin, Feng Xia. The Cultural Perspective and Translation Practice [M]. Beijing: National Defence Industry Press, 2007: 31.

[3] Agar, Micheal. The Intercultural Frame, unpublished ms.

[4] Agar, Micheal. The Biculture in Bilingual [M]. Language in Society, 1991:167-181.

[5] Nida, Eugine. Language and Culture [M]. Shanghai: Shanghai Foreign Education Press, 2005:38.

[6] Liu Miqing, Modern Translation Theory [M], Jiangxi Education Press, 1987

[7] Li Ruihua, the Comparative Research of English-Chinese Language and Culture [M], Shanghai Foreign Language Education Press, 1996. 